\title{
Competitive intelligence in support of strategic training and learning
}

\author{
D.F. Botha \\ Department of Information Science \\ School for Information Technology \\ University of Pretoria, Pretoria \\ deonie.botha@kioltd.com
}

\author{
J.A. Boon \\ Department of Information Science \\ School for Information Technology \\ University of Pretoria, Pretoria \\ hans.boon@up.ac.za
}

Key words: Competitive intelligence (CI), strategic training, knowledge processes, intellectual capital, strategic learning

Received: 26 May 2006

\section{Contents}

1. Introduction

2. Aim and methodology

3. Knowledge economy

4. Competitive intelligence

5. Strategic training

6. Strategic learning

7. Conclusion

8. References

\section{Introduction}

Tangible assets have always been a critical prerequisite for the competitiveness and the subsequent continued existence of companies. However, the long-term competitiveness of companies increasingly depends on its ability to identify, sustain and stimulate growth in value adding knowledge assets. Knowledge is the primary asset of the knowledge economy (Stewart 2001).

Knowledge assets include the knowledge of employees on their roles and responsibilities (human capital), knowledge about customers and suppliers (relationship capital), the knowledge embedded in databases, processes, structures, rules, routines (structural capital) and, more importantly, knowledge about competitors (competitive capital) (Bontis 2002; Rothberg and Erickson 2002). The sum total of these knowledge assets equals the amount and level of intellectual capital of companies. 
Strategic training preceded by a competitive intelligence (CI) process implies that the necessary emphasis is placed on ascertaining the nature of the emergent strategic environment of companies and the forces at play within the emergent strategic environment of companies. The focus is therefore long term in nature as opposed to the short term and tactical nature of CI that is sometimes found in companies.

\section{Aim and methodology}

The aim of this research was to establish the manner in which a CI process can be used by companies to ensure that strategic thinking is effective and that decision makers are able to learn about the emergent strategic environment of the company and its competitors. In this manner, the competitive capital of the company increases and the long-term competitiveness of the company is secured. By describing the variables involved in CI, the relationship between CI and strategic training and learning is identified.

The study integrated the findings of a literature study, in the management area, on CI with the findings of an empirical study. The empirical study identified the strategic training and learning needs of executives and managers in a selection of large South African companies (Botha 2007). By comparing these sets of findings the role of CI was identified in strategic training and learning.

\section{Knowledge economy}

Knowledge is the primary resource of companies in the knowledge economy; hence companies find themselves in an economy in which the primary resource is intangible. This explains why the knowledge economy is often referred to as an intangible economy (Andriessen 2004). The Organisation for Economic Co-Operation and Development (OECD) (1996) describes the knowledge economy as follows:

'The knowledge-based economy places great importance on the diffusion and use of information and knowledge as well as its creation. The determinants of success of enterprises, and of national economies as a whole, is ever more reliant upon their effectiveness in gathering and utilizing knowledge.'

This definition of the OECD (1996) explains the importance of knowledge on a micro- or organizational level as well as a macro- or national level.

Andriessen (2004) identifies seven characteristics of the knowledge economy. These seven characteristics clearly portray the role and importance of intangibles and knowledge in particular in the knowledge economy.

- Knowledge replaces labour and capital as a fundamental resource in production and intangibles, like brands, create a substantial part of the added value of companies.

- The knowledge content of products and services is growing rapidly.

- The intangible economy is an economy in which services are as important as products. Not only do products get more knowledge intensive, knowledge itself has become an important product as shown by the rise of the services industry.

- It is an economy in which the economic laws are different because intangibles need to be measured differently than physical and financial assets.

- The concept of ownership of resources has changed. Because knowledge mainly resides in the heads of employees, companies no longer own their most important resources.

- The intangible economy is an economy in which the characteristics of labour have 
changed. We have witnessed the rise of the knowledge professional.

- The management of intangible resources is fundamentally different from the management of tangible or financial resources.

From the above description of the knowledge economy it is clear that the long-term competitiveness of companies depend on their ability to identify, sustain and stimulate business critical knowledge assets. These knowledge assets form the intellectual capital of companies. The long-term competitiveness of companies depends to a large extent on the intellectual capital of companies and, in particular, the competitive capital of companies. CI enables companies to ascertain the nature of their emergent strategic environment and the competitors present in the strategic environment of companies. Subsequently strategic training should be used to develop the ability of decision makers to 'manage' effectively in the emergent strategic environment. The result of strategic training is known as strategic learning. Strategic learning increases the level of competitive capital of the company (Figure 1).

Figure 1 Competitive intelligence to competitive capital continuum

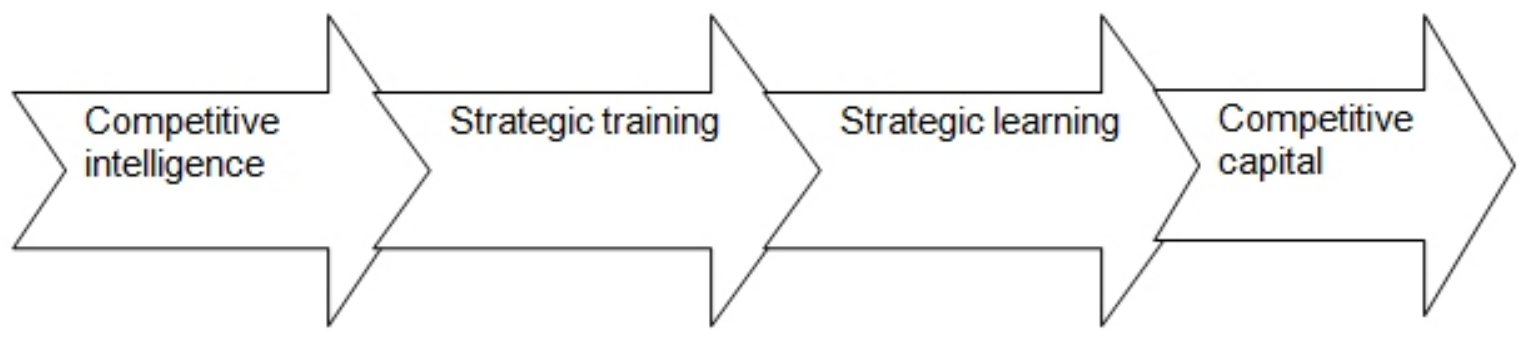

\section{Competitive intelligence}

Competitive intelligence is understood as a

'value added product resulting from the collection, evaluation, analysis, integration, and interpretation of all available information that pertains to one or more aspects of a decision maker's needs, and that is immediately or potentially significant to decision making' (Fleisher and Benssousan 2003).

Prescott (1999) defines CI as 'the process of developing actionable foresight regarding competitive dynamics and non-market factors that can be used to enhance competitive advantage'.

The CI process or cycle consists of the following seven phases (Figure 2):

- Intelligence needs and determining key intelligence topics: Ascertaining the intelligence needs of decision makers and narrowing down the intelligence needs of decision makers into key intelligence topics.

- Planning and direction: Planning and giving direction to further intelligence activities in order to fulfil the intelligence needs of decision makers.

- Collection: Collecting information available in open sources and by making use of human intelligence (HUMINT).

- Information processing: organization, systematization, implementing and maintaining a mechanism for the capturing and storage of information.

- Analysis: Analysing the collected information to ascertain the implications thereof for the decision maker. The analysis phase transforms information into intelligence by answering the 'so what?' question.

- Dissemination: Sharing and distributing the intelligence with decision maker. 
- Intelligence users and decision makers: The dissemination of intelligence will lead to the identification of new intelligence needs by users of intelligence and decision makers and the intelligence cycle or process will be activated again.

Figure 2 Competitive intelligence cycle (Brummer 2005)

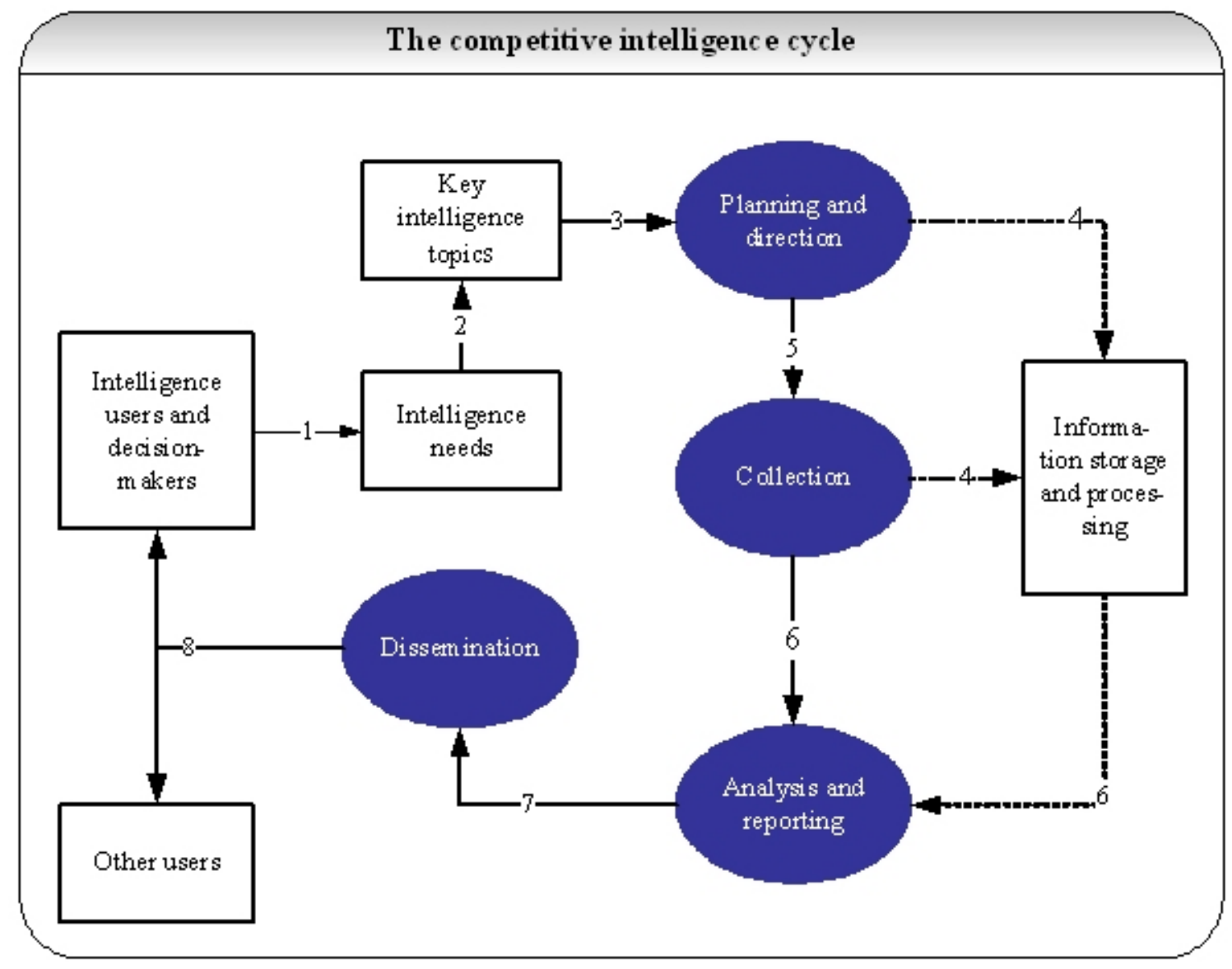

Porter (1998) states that for companies to remain or become truly globally competitive, it is recognized that information is required to support decisions on various levels of the organization. In a world of information overload, the emphasis is not on more information but on actionable intelligence, capable of guiding decisions in companies. CI should be positioned in the company to identify threats in the strategic environment capable of impacting negatively on the future of the company. A second and equally important function of CI is to identify new opportunities for the company, leading to innovation and ultimately benefiting the competitive status of the company.

Kahaner (1996) explains that intelligence may be required to attain a competitive advantage in a particular area of the company and could provide the company with a competitive edge by creating an advantage in one particular area of the company. Intelligence is required to make an executive decision on the future of the company in terms of, for example, a joint venture partnership. Intelligence may be required on an operational level to support a decision in terms of, for example, the price to purchase raw material or technological information for research and development purposes or marketing or competitor intelligence.

The nature of business and by definition CI under the strategic intent doctrine of competing and out-innovating the competitors should be offensive, not defensive. However, the opposite is unfortunately true. Gilad (1996) states that most companies are in a reactive mode, focused on identifying events after they had taken place rather than having a system of 'early warning' in place. Today, it is not enough to track the competitors, which is in essence a passive or defensive approach. The tracking of competitors are conducted to be able to create a model for 'competitive 
response modelling', implying much more than simple understanding - the implication is to anticipate actions, understanding intentions rather than tracking events. This strategy has proven to be very successful in the past. According to Schnaars (1994), the 'fast follower' strategy implies the need to fully understand the market leader and to build on its learning and mistakes. Evidence points to the fact that successful companies build 'layers' of competitive advantage rather than one transient advantage. These layers suggest constant search for new competitive advantages faster than the competition can copy the existing ones, and reducing risks by having a portfolio of advantages. Whatever the core strategy of the company - winning through competitive innovation or competitive imitation - both place enormous demands on an intelligence function. This decision has a direct impact on the intelligence process applied to support decisions in the company. In the case of competitive innovation, it radically alters the nature, scope and organizational relationships of CI in the company.

Business is driven by profit and in order to remain competitive, companies need not only to protect their interests, but also to expand their interests. They need to out-innovate their competitors. Prahalad and Hamel (1990) explain that competitive innovation is the 'art of containing competitive risks within manageable proportions'. To achieve this, it implies a fundamentally different approach in terms of expanding the interests of the institution. A new intelligence process for business is required, keeping in mind the fundamental differences and understanding the needs of business to be pre-active and to search for new opportunities. Prahalad and Hamel (1990) continue by depicting traditional competitor analysis in the West as outmoded, because it concentrates on existing resources. 'Assessing the current tactical advantages of known competitors will not help you understand the resolution, stamina, and inventiveness of potential competitors.'

Fuld (1995) explains CI is applied in companies, focusing on issues that may impact on the competitive environment of the institution, aimed at creating an early warning intelligence capability and supporting decision making.

According to Gilad (1996), the primary functions of a CI process are to:

- Build a new portfolio of competitive advantages against competitors' sustainable advantage

- Create a competitive surprise against incumbents

- Change the rules of an industry in order to unseat a leader

- Leverage resources through the use of partners

- Defend against competitors attempting to achieve surprise, the creation of new opportunities and changing the rules of engagement.

CI supports the strategic processes in companies, acting as sensor' to indicate to decision makers whether the organization is still competitive. This function of CI makes it a logical point of departure for a strategic training process.

\section{Strategic training}

Strategic training is aimed at decision makers who function on a corporate strategic level within the organizational hierarchy. During CI, the nature of the emergent strategic environment and the competitors at play in this environment is ascertained. This is followed by a strategic training process during which knowledge processes are conducted regarding the emergent strategic environment of companies.

Strategic training 'prepares employees and decision makers in particular for changes in job requirements wrought by external environmental conditions or by organisational policies, procedures plans, or work methods' (Rothwell and Kazanas 1994). This is due to the fact that not all employees are responsible for and partake in strategic thinking and learning in companies, 
however, they need to be informed and prepared for the dynamic nature and forces at play in the emergent strategic environment of companies.

Strategic training is dependent on the ability of various stakeholders (knowledge managers, CI practitioners, training practitioners) to translate the emergent strategic orientation of the company into the strategic training needs of decision makers on strategic level. Once the strategic training needs of decision makers have been addressed the process should be cascaded down to other levels of the company.

Rothwell and Kazanas (1994) explain that strategic training forms part of strategic human resource development. Strategic human resource development is best seen as the strategic management of training and development, and of management or professional education interventions, so as to achieve the objectives of the company while at the same time ensuring the full utilization of the detailed knowledge and skills of individual employees. It is concerned with the management of employee learning for the long term, keeping in mind the explicit corporate and business strategies.

Garavan (1991) and Garavan, Costine and Heraty (1995) describe the drivers of strategic human resource management in the following manner:

- New technology: technical changes in products, processes and information systems and market need for more rapid product development, etc.

- The drive for quality: business pressures for higher quality design of products and delivery of service, top-quality programmes requiring deeper understanding of international customer-supplier workings, etc.

- New competitive arrangements: changes in regulatory contexts such as privatization, deregulation, conversion to agency status, increase in strategic alliance and joint venture arrangements.

- Internationalization of business: globalization of business markets, etc.

- More flexible and responsive organization: decentralization in mature and declining industries, reduced rules and formalization, product and national boundaries within the organisation, etc.

- Supply of resources: educational provision unable to match organizational demand, growth of the 'me' culture with demand for individual development, etc.

The majority of the above-mentioned drivers of strategic human resource development, and therefore also strategic training, relate to the dynamics and forces at play in the emergent strategic environment of companies. Rothwell and Kazanas (1994) has developed a model, which was adapted by Botha (2007) for strategic training, which addresses the need for a training method by means of which decision makers can be prepared to deal with the dynamics and forces at play in the emergent strategic environment of companies. The following steps were identified:

Step 1: Identifying opportunities during which strategic training should be used Rothwell and Kazanas (1994) explain that strategic training should be used proactively to find a particular problem - or matter - that should be addressed through strategic training. Strategic training focuses on problem finding rather than problem solving.

These problems or matters are identified by asking the following questions:

- What should employees be doing in the future?

- What are employees actually doing?

- What differences exist between what employees should be doing in the future and what they are actually doing?

- How important are these differences? 
- What will be the cause of these differences?

- What should be done about training needs expected in the future?

- What should be done about strategic training needs? (Rothwell and Kazanas 1994).

During this step a comparison is made between the current versus the future performance of executives, managers and employees. However, before a particular problem or issue can be found which needs to be addressed by means of strategic training, it is necessary for companies to develop insight into the dynamic nature and forces at play within their strategic environment. This can be done by means of a CI process.

Step 2: Identifying the strategic training needs of decision makers and employees

Step 2 entails that the strategic training needs of decision makers involved in strategic processes are identified by individuals responsible for strategic human resource development and therefore also strategic training. When these training needs are properly identified and aligned with the strategic orientation of the company decision makers, employees should be enabled for effective performance in the future. Each of the identified strategic training needs must be analysed in terms of aspects such as:

- The precise nature and scope of strategic training needs of executives and managers

- The level of criticality of each of the identified strategic training needs or the importance of addressing a particular need

- The strategic environment in which the need has been identified. Training needs to follow from ordered domains and are probably less complex to address than training needs that flow from complex and chaotic domains (Botha 2007).

\section{Step 3: Determining key characteristics of learners}

Rothwell and Kazanas (1994) explain as follows: 'Employees presently working in a job may well be affected by changes in job duties and performance requirements resulting from changes in business strategy or external environmental conditions.' But if the emphasis is on the future, some employees will be gone - moved out of the job class - by the time changes are felt. Other employees will be moving into the job class. It is therefore necessary to predict who the learners will be. Four aspects on which the decision to include learners in a strategic training process should form the bases. These aspects are ability, motivation, necessary base of skills and strategic thinking skills.

\section{Step 4: Analysing the future [work] setting}

The nature and scope of strategic training should reflect the future working environment or setting in which decision makers will apply their newly acquired skills. Rothwell and Kazanas (1994) explain why a training environment should be created that reflects the future work setting of decision makers:

'The idea is to use the instructional setting to simulate future, but not yet existing, job conditions, so that learners gain experience without incurring the costly consequences of doing so in a real setting'.

Botha (2007) verified this in the identification of training needs of executives in South Africa. An analysis of the nature of the work decision makers will be responsible for in future should commence as soon as the future work setting has been analysed. Step 5 will ensure that the work which executives and managers perform in future enable the company to achieve its future strategic orientation. Steps 4 entails that the emergent strategic orientation of the company is translated into a future work setting and an analysis of work that needs to be done in future.

\section{Step 5: Preparing strategic instructional objectives}

The objectives of the training or the outcomes that are to be achieved through strategic training or 'what learners will be able to do upon completion of a learning experience' are determined during Step 5 of the Rothwell and Kazanas (1994) model. Rothwell and Kazanas (1994) explain that the 
strategic instructional objectives should address a discrepancy in the skills of decision makers and employees. They describe this discrepancy as follows:

'Instead of expressing [addressing] a discrepancy between what is and what should be at present, a strategic instructional objective is based on a discrepancy between what is at present and what should be in future.'

\section{Step 6: Arranging strategic training objectives and assessment}

The order in which the training objectives, which were determined in Step 5, will be addressed is determined by the aim to be achieved by the training. The aim of strategic training varies from creating knowledge to sharing knowledge regarding the emergent strategic orientation of the company. As soon as the sequence in which the training needs of decision makers should be addressed has been determined, suitable instructional methods and media must be found to address these training needs. Methods should be developed to assess the effectiveness and relevance of strategic training.

\section{Step 7: Selecting and using appropriate delivery methods}

The aim of the training determines the type of delivery methods used to present strategic training to decision makers. As soon as the content that has to be conveyed to decision makers have been prepared, the delivery method that will be used to present the content to executives, managers and employees needs to be identified (Botha 2007).

\section{Step 8: Preparing and selecting content for strategic training}

The content of training depends on the nature of the training needs, the future work setting and future work of decision makers. Content can be developed and prepared internally or be bought from commercial suppliers of training material. However, in some cases the content requires the presence of a learning facilitator in order to stimulate the creation of new knowledge. The nature of the content is described as follows: 'stems from the "training" session and is a function of group interaction and methods used to elicit new ideas' (Rothwell and Kazanas 1994). The successful presentation of training is largely determined by the training skills of the trainer but in some cases the trainer is mostly a facilitator while the 'content' of the training is transferred by the participants or learners involved in the training process.

The outcome or result of a strategic training process preceded by CI is strategic learning. This implies that decision makers have learned as regards the emergent strategic orientation of the company (Botha 2007).

\section{Strategic learning}

The ability of companies to develop a sustainable or long-term competitive advantage is becoming increasingly rare. Companies can easily lose a competitive advantage which has been arduously achieved. In such circumstances, it is important to note that developing a competitive advantage invariably depends on learning and is predicted by learning. As the rapidly evolving competitive environment of companies has such an immense influence on it, it is essential for companies to constantly monitor and learn about the competitive environment.

Gilad (1994) emphasizes that the competitive environment continuously sends out signals about change, trends, prospects, threats and weaknesses. Initially these signals are weak, ambiguous and hidden. Learning organizations (Senge 1990) harness the power of continued learning to fight decline and create a sustainable competitive advantage. In contrast, Fuld (1995) believes that there is no excuse for competitive surprises. The professional sports industry is a case in point and has long recognized the value of 'learning about the dynamic changes in the competitive environment' and the need to adapt its strategies accordingly and continuously' (Tyson 1998). 
The capability of companies to learn about events in the competitive environment can be defined as follows (adapted from Fahey 1999): Continuous learning about change in and around competitors, customers, suppliers, distribution channels, alliances, technology, and the social, political and economic milieu, which should furnish the organization with an understanding or insight of the current and future competitive context, as well as supplying key inputs in developing alternative futures, which can be translated into business environment opportunities.

Strategic learning is a complex process because of its pervasiveness, discontinuity and unpredictability. This is why companies should not be content solely with the generation of knowledge. The knowledge in companies rapidly becomes obsolete, skills stagnate and capabilities and competencies deteriorate if there is no systematic attention to learning. In referring to this phenomenon, Fahey and Randall (1998) concur that the single greatest liability of management teams in many companies is that they confront complex dynamic realities with an approach designed for simple static problems. Consequently, these two authors argue that the basic purpose of a learning organisation to continually expand and create its future. Bearing these realities in mind, strategic learning should have the following implicit characteristics.

- Learning should be continuous. It is therefore a journey, not a destination, because change in the organization's external and internal environment is unrelenting, pervasive and unpredictable. As soon as learning begins to stagnate, a company's knowledge begins to slide into mythology.

- It should be a cognitive process. In such an environment, analysts and decision makers attempt to make sense of the world around them. To this end, they select and order data; they attribute meaning to data; they draw inferences from incomplete data and partial analysis; and they continually challenge their prior stock of knowledge in the context of identifying possible opportunities.

- It should be a collective process. True learning about the competitive environment occurs when individuals share their knowledge, challenge one other and reflect on one another's judgements and assessments.

- It should not be dissociated from decision making. Learning and doing are inseparable. Knowledge generation and knowledge use are inextricably interrelated. Learning generates knowledge, which is embodied in action; action, in turn, generates further knowledge and learning.

- It should not merely concern accumulating data about the competitive environment, no matter how new or unrelated the various data items are. Real knowledge and insight are gained by capturing the underlying structures - the patterns that are revealed by means of ordering, selecting and interpreting data.

- Lastly, strategic learning is not an end in itself. It is intended to improve the understanding of the interface between the company and its emergent strategic environment (Fahey 1999).

Against the above background, it is worth noting that strategic learning is the outcome of a structured, dynamic and, significantly, a conscious CI process followed by a strategic training process. Only in this way can a company augment its stock of competitive capital and create a long-term competitive advantage.

\section{Conclusion}

Strategic training and learning, which is long term, should be supported by CI which is short term. CI is not enough. The strategic training needs of executives and managers should be continuously identified and addressed (Botha 2007).

In the knowledge economy, powerful forces such as globalization, technological advances and trade liberalization are increasing the pace and altering the shape of business across the world. In 
circumstances where uncertainty, turbulence and aggressive competition have become the global norm, traditional organizations will not survive this continuous competitive onslaught if they do not respond proactively and creatively. The time may have come for organizations to reconsider their competitive strategies, away from the typical head-on approach in a cut-throat competitive environment.

Focusing upon two strategies, namely CI and strategic training, competitive learning could play a significant role in such a shift in organizational strategic thinking. In Figure 1 it is explained that competitive capital builds on learning which, in its own right, builds on strategic training, which again is based on CI. CI is a short-term solution to the intelligence needs of an organization while strategic training is a long-term solution to ensure the competitiveness of an organization. This creative approach to competitive learning could create a situation where William Gibson's words would have a whole new meaning (1999):

'The future is already here, it is just unevenly distributed.'

\section{References}

Andriessen, D. 2004. Making sense of intellectual capital: designing a method for the valuation of intangibles. Burlington: Elsevier Butterworth-Heinemann.

Botha, D.F. 2007. The strategic continuing training needs of executives and managers in a selection of large South African companies. Doctoral thesis. Pretoria: University of Pretoria. [Unpublished].

Bontis, N. 2002. Managing organisational knowledge by diagnosing intellectual capital: framing and advancing the state of the field. In: Bontis, N. (ed.). 2002. World congress on intellectual capital readings. Boston: Butterworth-Heinemann.

Brummer, H.L. 2005. A dynamic competitive analysis model for a global mining firm. Pretoria: Unisa.

Fahey, L. 1999. Outwitting, outmanuevering and outperforming competitors. New York: Wiley.

Fahey, L. and Randall, R.M. 1998. Learning from the future: competitive foresight scenarios. New York: Wiley.

Fleisher, C.S. and Bensoussan, B.E. 2003. Strategic and competitive analysis: methods and technique for analysing business competition. New Jersey: Prentice Hall.

Fuld, L.M. 1995. The new competitor intelligence: the complete resource for finding, analyzing, and using information about your competitors. New York: Wiley.

Garavan, T.N. 1991. Strategic human resource development. Journal of European industrial training15(1):17-30.

Garavan, T.N., Costine, P. and Heraty, N. 1995. The emergence of strategic human resource development. Journal of European Industrial Training 19(10):4-10.

Gibson, W. 1999. Talk of the nation. National Public Radio. 30 November 1999. Cited in The next frontier of innovation, 2005, New York: McKinsey \& Company.

Gilad, B. 1996. Business blindspots: replacing your company's entrenched and outdated myths, beliefs and assumptions with the realities of today's markets. Chicago, Illinois: Probus

Publishing Company. 
Kahaner, L. 1996. Competitive intelligence: how businesses gather, analyze, and use information in the global market place.New York: Simons \& Schuster.

Organisation for Economic Co-Operation and Development. 1996. The knowledge-based economy. Paris: OECD.

Porter, M.E. 1998. On competition. Boston: Harvard Business School Publishing.

Prahalad, C.K. and Hamel, G. 1990. The core competence of the corporation. Harvard Business Review, May/June. Boston: Harvard Business School Publishing.

Prescott, J.E. 1999. The evolution of competitive intelligence: designing a process for action. APMP (Spring):37-52.

Rothberg, H.N. and Erickson, G.S. 2002. Competitive capital: a fourth pillar of intellectual capital. In: Bontis, N. (ed.). 2002. World Congress on Intellectual Capital readings. Boston: Butterworth-Heinemann: 94-103.

Rothwell, W.J. and Kazanas, H.C. 1994. Human resource development: a strategic approach. Rev. ed. Amherst, Ma: Human Resource Development Press.

Schnaars, S.P. 1994. Managing imitation strategies. New York: Free Press.

Senge, P.M. 1990. The fifth discipline: the art and practice of the learning organization. New York: Bantam, Doubleday Dell Publishing Group.

Stewart, T.A. 2001. The wealth of knowledge: intellectual capital and the twenty-first century organisation. London: Nicholas Brealey.

Tyson, K.W.M. 1998. The complete guide to competitive intelligence. Chicago: Kirk Tyson International.

ISSN 1560-683X

Published by InterWord Communications for Department of Information and Knowledge Management, University of Johannesburg 